\title{
Endoscopic Stenting of Malignant Biliary Obstruction and Its Impact on Quality of Life
}

\author{
Authors \\ Rajesh R.U ${ }^{1}$, K.Premkumar ${ }^{2}$, Caroline Selvi ${ }^{3}$ \\ Madras Medical College, Chennai
}

\begin{abstract}
Background: Endoscopic stent insertion is considered one of methods for palliation of malignant bile duct obstruction (MBDO).The aims of this study were to determine clinical characteristics that have the greatest adverse impact on quality of life in patients with malignant biliary obstruction, and to quantify changes in the quality of life of patients with malignantbiliary obstruction after successful decompression with a plastic stent.

Patients and Methods: Patients undergoing endoscopic retrograde cholangiopancreatography for MBDO completed the Functional Assessment of Cancer Therapy-General questionnaire at baseline, at 1 month after stent insertion and was used to quantify quality of life.
\end{abstract}

\section{Introduction}

Most malignant tumors causing bile duct obstruction, such as pancreatic adenocarcinoma, gallbladder carcinoma, or cholangiocarcinoma, have an extremely poor prognosis. ${ }^{1,2}$ At the time of diagnosis the majority of these tumors will be unresectable, with a median survival of 4 to 6 months ${ }^{3}$ Biliary obstruction develops in $70-90 \%$ of cases, causing severe pruritis and shortens survival by leading to nutritional disturbances, progressive liver failure, cholangitis and coagulopathy. Thus in most patients the primary goal remains to relieve biliary obstruction by surgical, radiological and endoscopic means, and maintaining quality of life in the few months between diagnosis and death. Further technical improvements are required to solve the most important clinical problem of late stent occlusion. New developments such as expandable metallic stents and refinements in existing equipments and techniques have already resulted in measurable gains and hold great promise for future expansion of their use in malignant gastric outlet obstruction secondary to tumor infiltration of the duodenum. Corresponding advances are being made in the field of percutaneous transhepatic intervention and Hepatobiliary surgery such that further prospective randomized trials are necessary to define optimal therapy ${ }^{[4][5][6][7]}$. Endoscopic stent insertion safely and effectively re-establishes bile flow, alleviates jaundice and pruritis and may improve quality of life and thus favoured for palliation of malignant biliary obstruction. Endoscopic insertion of a plastic or metal stent is technically successful in $90-95 \%$ of patients with malignant extrahepatic biliary obstruction. Plastic stents are used because of their efficacy and low cost. These stents are exchanged easily as long as there is no duodenal obstruction. A few available studies have demonstrated improved QOL in stented patients. $^{8-11}$ 
This prospective analysis was undertaken to study possible relationships between presenting symptoms and baseline QOL. Also examined were the possible predictive abilities of these baseline variables on the subsequent outcome of QOL after successful biliary decompression with a plastic stent

\section{Materials and Methods}

Patients with malignant biliary obstruction without liver metastasis and considered non-surgical candidate admitted to the department of Gastroenterology, Madras medical college for endoscopic palliation were recruited. This was a prospective study from February 2019 to April 2020. Diagnosis was initially made on the basis of typical history, clinical examination, abdominal USG and CT, which was substantiated by MRCP, if deemed necessary, and ERCP at the time of stenting. All the patients were offered stenting, patients who refused stenting where not included. The diagnosis of malignancy was established by:

1) Cytology/histology of the tumor at ERCP or operative biopsy.

2) FNAC of accessible sites like lymph nodes, ascites etc.

3) Imaging (USG, CT, MRI/MRCP or ERCP later) suggestive of malignancy.

\section{Inclusion Criteria}

1) Clinical data and history suggestive of malignant bile duct obstruction, found to be unresectable after investigations.

2) Bilirubin level $>9 \mathrm{mg} / \mathrm{dL}$.

3) Investigations: USG and CT or MRI performed before inclusion.

\section{Exclusion Criteria}

1) Informed consent not obtained.

2) Unable or unwilling to follow-up.

3) Proper investigations not performed.

4) Candidate for surgical resection or suspected non-malignant obstruction.

5) Bilroth type II gastric resection, pyloric or duodenal obstructions.

6) Uncorrectable coagulopathy excluding sphincterotomy.

7) Previous biliary stenting.
8) Surgery within 4 weeks of induction into study.

\section{Endoscopic Intervention}

All ERCPs were performed with a therapeutic duodenoscope. The bile duct was cannulated and stricture locationand length were determined. A guide wire was advanced proximal to the stricture, a biliary sphincterotomy was performed at the discretion of the endoscopist, and the patient was then randomized to placement of a 10 or an $11.5-\mathrm{Fr}$ biliary plastic stent. Technical success was defined as the passage of the stent across the stricture and the flow of contrast and/or bile through the stent. Clinical success was defined as a drop in bilirubin level to $<75 \%$ of baseline within 2 weeks after stent insertion. Routine stent exchanges were not scheduled; however, if the patient developed signs and symptoms suggestive of stent occlusion (eg, cholangitis, jaundice) the stent was changed on an urgent basis.

\section{QOL outcome}

The primary outcome was a documented change in QOL assessment over the first month after successful biliary drainage compared with that before decompression. Administration of the SF-36 Quality of Life scale at baseline and 1 month after stent insertion was used to assess this outcome. The SF-36 Health Survey (Medical Outcomes Trust, Inc., Boston, Mass.) is a multi-item scale measuring 8health domains: physical functioning (PF), role limitations because of physical health problems (RP), bodilypain (BP), general health $(\mathrm{GH})$, vitality (VT), social functioning (SF), role limitations because of emotional problems (RE), and overall mental health $(\mathrm{MH})$. This QOL measurement tool was selected as it has been extensively validated in populations with other cancers including breast, prostate, and tumors of the head and neck. Standardized scores for each of the 8 health domains are interpreted in relation to means and standard deviations in the general adult population of the United States. ${ }^{12}$ Variables evaluated in relation to the observed QOL changes included 
clinical characteristics such as the presenceor absence of weight loss, jaundice, pruritus, abdominal pain, and anorexia (quantified by the percentage of skipped meals); body mass index (BMI) (in $\mathrm{kg} / \mathrm{m} 2$ ); duration of symptoms; the site of biliary obstruction, and length of polyethylene (plastic) stent inserted. Collected data also included the following standard biochemical parameters: total bilirubin (TB), alkaline phosphatase (AP), $\gamma$ glutamyltranspeptidase (GGT), aspartate aminotransferase (AST), alanine aminotransferase (ALT), hemoglobin, white blood cell, and plateletcounts. These data were obtained at initial presentation and at visits 7 days and 1 month after biliary decompression.

\section{Statistical analysis}

Descriptive analysis was conducted by comparing the means and standard deviation of baseline values of QOL in each domain with its corresponding value 1 month after stent insertion. As well, the Kruskal-Wallis one-way analysis of variance (ANOVA) was performed to compare the individual domains of the SF-36 to the grouped clinical and biochemical variables of interest (e.g., by gender, location of obstruction). The chi-square test was used tocompare proportions among the clinical characteristics. The Pearson correlation was used to quantify the improvement in the individual domains of the SF-36 with the improvement in total bilirubin in which baseline bilirubin was dichotomized at its median value to divide the cohort into those with a "high baseline bilirubin" versus "low baseline bilirubin." With this clinical cut-off, analysis was conducted to ascertain the association between improvement in baseline bilirubin and its effect on each domain of the SF-36 1 month after stent insertion. This analysis was conducted for both those patients who achieved successful biliary drainage (as defined above) and in the entire cohort. Once significant variables were identified by univariate analysis, clinically significant variables were considered in the creation of predictive models. Multivariate analysis was then performed to identify models predicting improved quality of life.

\section{Results}

\section{Study Population}

Sixty four patients (25 men, 39 women) were prospectively enrolled in the study. Mean age at enrollment was 68.4 years (SD 9.4 years). The mean weight of the cohort was $58.4 \mathrm{~kg}$ (SD $11.8 \mathrm{~kg}$ ) and the mean BMI was $22.5 \mathrm{~kg} / \mathrm{m} 2$ (SD $4.7 \mathrm{~kg} / \mathrm{m} 2$ ).

At baseline, $54 \%$ of patients complained of pruritus and $98 \%$ were jaundiced. Anorexia was reported by $32 \%$ and $82 \%$ had an ASA score of 3 or an ECOG score of 4. All had hyperbilirubinemia (mean bilirubin $16 \mathrm{mg} / \mathrm{dL}$ [8.1 mg/dL]). The mean duration of symptoms was 26 days. Subjective weight loss was noted by $80 \%$ of patients (Table 1). The baseline scores for each of the 8 domains of the SF-, 36 scores closer to100 suggest few problems in a domain, or the absence of a negative state (limitation, disability, or pain). All baseline domain scores for the study population were significantly lower (table 2)

Among the 64 malignancies diagnosed there were 26 pancreatic cancers, 22 distal cholangio carcinoma, 5 tumors of the GB, 5 extra hepatic bile duct obstruction because of malignant nodal compression at or distal to the hepatic hilum, 7 hilarcholangio carcinoma. In no case was there overt liver metastases at enrollment. Endoscopic sphincterotomy was performed in $22 \%$ of patients to facilitate stent placement. There were no complications after the procedure related to biliary stent placement among the 64 patients.

By using ANOVA, baseline characteristics were identified that were strongly associated with poor QOL (as defined by significantly lower scores compared with 1 month post stenting). All8 domains of the SF-36 were adversely associated with the presence of weight loss $(\mathrm{p}<0.05)$ and abdominal pain $(p<0.05)$. In comparison, an elevated bilirubin level correlated with poor scores in the domains of physical role $(\mathrm{p}=0.011)$, vitality $(\mathrm{p}=0.042)$, and social function $(\mathrm{p}=0.005)$. No other clinical or biochemical characteristics were statistically significant.

Logistic regression modeling techniques were used to identify which of the 3 characteristics were 
independently predictive of a poor QOL before stent insertion. The presence of weight loss at baseline resulted in a statistically significant deterioration of QOL scores in the domains of general health ( $\mathrm{p}=$ 0.001) and physical role ( $p=0.001)$. Multivariate analysis using the BIC criterion ${ }^{13}$ revealed that the variable of weight loss was featured in $100 \%$ of the best models of general health and physical role, and in $79.8 \%$ of the best models of emotional role.

The presence of baseline hyperbilirubinemia also resulted in a significant deterioration in QOL scores in the domains of social function $(p=0.005)$ and physical role $(\mathrm{p}=0.006)$ as shown by regression modeling. By using the BIC, multivariate analysis revealed that hyperbilirubinemia dominated in96.2\% of the best models of social function and in $91.3 \%$ of the best models of physical role.

The presence of baseline abdominal pain did not show a significant association with baseline QOL when subjected to multivariate analysis with either linear regression or BIC methodology.

\section{One month after stent insertion}

Complete data were available for 52 of the 64 patients at the 1-month assessment. Of the 12 patients for whom no 1-month data are available: 6 died before the 1-month visit, 6 were withdrawn because of stent blockage. Of the patients who failed to complete the 1-month evaluation, $40 \%$ were men .Others who completed 1-month assessment, $62 \%$ were men (mean age 72 years)

Among the remaining patients, 2 subgroups were identified that benefited best in terms of QOL improvements after biliary stent insertion (Table 3). The first group, patients with a "low baseline" bilirubin $(<13 \mathrm{mg} / \mathrm{dL})$, had a mean improvement of 20points (26.4 points) in Social Function scores after stent insertion. By comparison, patients with a "high baseline bilirubin" ( $>13 \mathrm{mg} / \mathrm{dL}$ ) had a mean deterioration of 5 points in the Social Function scores after stent placement $(\mathrm{p}=0.03)$. The second subgroup, the $78 \%$ of patients in whom drainage was successful, had improvement in QOL in the domains of Social Function $(p=0.03)$ and Mental
Health $(\mathrm{p}=0.03)$. For the remaining 6 domains, there was no significant associated improvement.

Table 1 Baseline characteristics of study population

\begin{tabular}{|c|l|}
\hline Characteristic Total & $\mathrm{n}=64$ \\
\hline Mean age (SD) & 68.4 years \\
\hline Female gender (\%) & $60 \%$ \\
\hline Mean weight (kg) (SD) & $58.4 \mathrm{~kg}$ \\
\hline Mean BMI (kg/m2) (SD) & $22.5 \mathrm{~kg} / \mathrm{m} 2$ \\
\hline Mean duration of symptoms (d) (SD) & 26 days \\
\hline Pruritus (\%) & $54 \%$ \\
\hline Jaundice (\%) & $98 \%$ \\
\hline Weight loss (\%) & $80 \%$ \\
\hline Abdominal pain (\%) & $24 \%$ \\
\hline
\end{tabular}

Table 2 Comparison of QOL scores before and after biliary decompression

\begin{tabular}{|l|l|l|}
\hline Domain & Baseline mean(SD) & $\begin{array}{l}1 \text { month after stent } \\
\text { mean(SD) }\end{array}$ \\
\hline Body pain & $54.5(30.2)$ & $64.4(24.8)$ \\
\hline General health & $55.2(24.6)$ & $48.5(22.3)$ \\
\hline Mental health & $59.5(23.2)$ & $68.4(21.6)$ \\
\hline Physical function & $48.2(29.7)$ & $75.6(24.7)$ \\
\hline Role physical & $28.4(32.2)$ & $24.3(22.2)$ \\
\hline Role emotional & $40.6(42.4)$ & $61.7(29.5)$ \\
\hline Social function & $48.6(37.6)$ & $58.6(31.1)$ \\
\hline Vitality & $44.3(21.5)$ & $48.2(26.8)$ \\
\hline
\end{tabular}

Table 3 Multivariate analysis of risk factors on baseline QOL

\begin{tabular}{|l|l|l|l|}
\hline Variable & QoL Domain & $\begin{array}{l}\text { Relative risk } \\
{[95 \% \mathrm{CI}]}\end{array}$ & p Value \\
\hline $\begin{array}{l}\text { Weight loss } \\
\text { No* }\end{array}$ & $\begin{array}{l}\text { General } \\
\text { health }\end{array}$ & $\begin{array}{l}1.0[0.0] \\
27.4(11.4,74.0)\end{array}$ & 0.001 \\
\hline $\begin{array}{l}\text { Weight loss } \\
\text { No* } \\
\text { Yes }\end{array}$ & Physical role & $\begin{array}{l}1.0[0.0] \\
39.3(11.2,66.4)\end{array}$ & 0.001 \\
\hline $\begin{array}{l}\text { Weight loss } \\
\text { Yo* } \\
\text { Yes }\end{array}$ & $\begin{array}{l}\text { Emotional } \\
\text { role }\end{array}$ & $\begin{array}{l}1.0[0.0] \\
37.4(16.1,65.3)\end{array}$ & 0.018 \\
\hline $\begin{array}{l}\text { Hyperbilirubinemia } \\
\text { No* } \\
\text { Yes }\end{array}$ & Physical role & $1.0[0.0]$ & 0.006 \\
\hline $\begin{array}{l}\text { Hyperbilirubinemia } \\
\text { No* } \\
\text { Yes }\end{array}$ & $\begin{array}{l}\text { Social } \\
\text { function }\end{array}$ & $\begin{array}{l}1.0[0.0] \\
10.3(6.5,33.4)\end{array}$ & \\
\hline
\end{tabular}

*Reference category 


\section{Discussion}

Hyperbilirubinemia is one of the most important clinical consequences of MBDO. It is associated with a number of physiological ramifications ${ }^{14}$ including renalimpairment, ${ }^{15}$ immune dysfunction, ${ }^{16}$ jaundice, pruritus, anorexia, and weight loss, ${ }^{17}$ all of which may adversely impact QOL. Endoscopic biliary stenting has become a standard treatment for MBDO, producing fewer complications than surgical bypass. ${ }^{18}$ Despite the improved patency of metal stents, plastic stents are still widely used as an initial treatment, being especially cost effective in patients with an estimated survival of $<4$ months, and in countries with low-cost ERCP. ${ }^{19}$ The quantification of the benefits in QOL achievable by biliary stent placement is important, as the main focus of this therapy is maximizing the patients' sense of well-being, rather than prolongation of the patients' life.

Previous studies have suggested improvement in different aspects of QOL after endoscopic stenting. Ballinger et $\mathrm{al}^{13}$ used a 3-part questionnaire including the Rotterdam Symptom Checklist and Hospital Anxiety and Depression Scale, in 19 patients with pancreatic cancer. They showed that biliary stenting improved symptoms such as anorexia, indigestion, and weight loss and improved QOL. Luman et al $^{15}$ administered the European Organization for Research and Treatment of Cancer QOL questionnaire to 38 patients with MBDO before and 1 month after endoscopic tenting. In addition to the expected improvement inpruritus and jaundice, the patients also reported significant improvement of anorexia, diarrhea, and sleep pattern. Emotional, cognitive, and global health scores were significantly improved as well. The impact of endoscopic stenting on the QOL in MBDO by Abraham et al $^{22}$ used the 36-Item ShortForm Health Survey (SF-36) at baseline and 1 month after stent insertion and it demonstrated significant improvements in social function and mental health as in our study.

With use of the SF-36, the presence of weight loss and hyperbilirubinemia at baseline were identified has having the greatest negative impact on QOL. In the present study, all patients with radiographic evidence of metastatic disease to the liver were excluded because jaundice in these patients would not be expected to respond to biliary decompression ${ }^{23}$. The present study quantified the impact of successful decompression on the different physical, psychologic, and social components of QOL. No threshold was identified with regardto an effect on the mental health domain.

As in other studies of patients with cancer, there may be a psychologic benefit associated with participationin a clinical trial that may impact subsequent mental health assessment (SF) after decompression. ${ }^{27}$ Anypsychologic benefit, however, should not invalidate the observation in this trial concerning the differential outcome among patients with high- versus low-baseline bilirubin.

In conclusion, weight loss and hyperbilirubinemia are baseline clinical characteristics that negatively impact baseline QOL. The present study also quantifies expected improvements in QOL domains (social function and mental health) after biliary decompression. This information may improve patient counseling and selection of patients for possible palliative therapies. These findings may result in a more adapted selection of patients for endoscopic biliary decompression

\section{References}

1. Jemal A, Thomas A, Murray T, et al. Cancer statistics 2002.CA Cancer J Clin. 2002; 52:23-47.

2. Lowy AM. From bad to worse: prognostic factors in pancreatic cancer. Ann Surg Oncol. 2004;11:117-118.

3. Lowenfels AB, Maisonneuve P, Boyle P. Epidemiology of pancreatic cancer. In: Howard J, Idezuki Y, Ihse I, et al, eds. Surgical Diseases of the Pancreas. 3rd ed. Baltimore: Lippincott Williams \& Wilkins; 1998:433-439

4. Warshaw AL, Fernandez-del Castillo C. Pancreatic Carcinoma. N Engl J Med 1992; 326:455-465. 
5. Smith AC, Dowsett JF, Russell RC. Randomized trial of endoscopic stenting vs. surgical bypass in malignant bile duct obstruction. Lancet 1995: 344:1655-1660

6. Linchtenstein DR, Carr-Locke DL. Endoscopic palliation of unresectable pancreatic carcinoma. Surg Clin North Am 1995; 75:969-988.

7. Michael J. Levy, Todd H. Baron, Christopher J. et. al. Clinical Gastroenterology and Hepatology 2004; 2:273-285.

8. Ballinger $\mathrm{AB}, \mathrm{McHugh} \mathrm{M}$, Catnach SM, et al. Symptom reliefand quality of life after stenting for malignant bile duct obstruction. Gut. 1994;35:467-470.

9. Pereira-Lima JC, Jakobs R, Maier M, et al. Endoscopicstenting in obstructive jaundice due to liver metastases: does ithave a benefit for the patient? Hepatogastroenterology. 1996;43:944-948.

10. Luman W, Cull A, Palmer KR. Quality of life in patients tented for malignant biliary obstructions. Eur J Gastroenterol Hepatol. 1997;9:481-484.

11. Abraham NS, Barkun JS, Barkun AN. Palliation of malignantbiliary obstruction: a prospective trial examining impact onquality of life. Gastrointest Endosc. 2002;56:835841.

12. Ware JE, Snow KK, Kosinski M, Gandek B. SF-36 health survey manual and interpretation guide. Boston: The Health Institute, New England Medical Center; 1993. p. 87.

13. Kass R, Raftery A. Bayes factors. J Am Stat Assoc 1995;90:773-95.

14. Rege RV. Adverse effects of biliary obstruction: implications for treatment of patients with obstructive jaundice. AJR Am J Roentgenol. 1995;164:287-293.

15. Kramer HJ. Impaired renal function in obstructive jaundice:roles of the thromboxane and endothelin systems. Nephron.1997;77:1-12.
16. Jiang WG, Puntis MC. Immune dysfunction in patients withobstructive jaundice, mediators and implications for treatment.HPB Surg. 1997;10:129-142.

17. Cotton PB, Schmitt C. Quality of life in palliative management of malignant obstructive jaundice. Scand J Gastroenterol.1993;199:44-46.

18. Moss AC, Morris E, Leyden J, et al. Malignant distal biliaryobstruction: a systematic review and meta-analysis of endoscopicand surgical bypass results. Cancer Treat Rev. 2007;33:213-221.

19. Yeoh KG, Zimmerman MJ, Cunningham JT, et al. Comparative costs of metal versus plastic biliary stent strategies for malignant obstructive jaundice by decision analysis. Gastrointest Endosc. 1999;49: 466-471.

20. Ballinger AB, McHugh M, Catnach SM, et al. Symptom reliefand quality of life after stenting for malignant bile ductobstruction. Gut. 1994;35:467-470.

21. Luman W, Cull A, Palmer KR. Quality of life in patients tented for malignant biliary obstructions. Eur J Gastroenterol Hepatol. 1997;9:481-484

22. Abraham NS, Barkun JS, Barkun AN. Palliation of malignant biliary obstruction: a prospective trial examining impact on quality of life. Gastrointest Endosc. 2002;56:835-841.

23. Davids P, Groen A, Rauws F, Tytgat GN, Huibregtse K.Randomised trial of selfexpanding metal stents versus polyethylene stents for distal malignant biliary obstruction. Lancet 1992;340:1488-92. 